\title{
How vegans, vegetarians and carnists differ in personality traits and attitudes towards animals
}

\author{
L'uboš Kováč ${ }^{A, B, C, D, E, F}$, Peter Halama $\mathbb{1 D}^{A, C, D, E, G}$ \\ University of Trnava, Trnava, Slovakia
}

\section{BACKGROUND}

Food decisions and dietary preferences are affected by a complex set of different cultural or regional factors, but personality traits seem to play an important role too. Previous research suggested that the food preferences related to veganism, vegetarianism, or carnism can be predicted by the Big Five model of personality and reflected in the attitudes towards animals.

\section{PARTICIPANTS AND PROCEDURE}

The present study examined personality traits and attitudes towards animals of $190(M=24.90, S D=7.18)$ Slovak participants, of whom 57 were vegans, 56 vegetarians, and 77 carnists. To measure Big Five personality traits, the Big Five Inventory-2 (BFI-2) was used. Attitudes towards animals were measured by the short 10-item version of the Animal Attitude Scale (AAS-10).

\section{RESULTS}

Vegans and vegetarians scored significantly higher than carnists in open-mindedness and attitude towards ani-

mals; there was no difference between scores of vegans and vegetarians. No relationship between the diet groups and demographic variables (gender, education, and age) was identified. From personality traits and sociodemographic variables, only open-mindedness was a significant predictor of attitudes towards animals.

\section{CONCLUSIONS}

Vegans and vegetarians differ from carnists primarily in one trait: open-mindedness. Vegans and vegetarians also differ from carnists by holding more positive attitudes towards animals.

\section{KEY WORDS}

personality traits; attitudes towards animals; vegetarians; vegans; carnists

CORRESPONDING AUTHOR - Peter Halama, Faculty of Philosophy, University of Trnava, Hornopotočná 23, 91843 Trnava, Slovakia, e-mail: peter.halama@truni.sk

AUthors' CONTRIBUtion - A: Study design - B: Data collection - C: Statistical analysis - D: Data interpretation .

E: Manuscript preparation · F: Literature search · G: Funds collection

TO CITE THIS ARTICLE - Kováč, L., \& Halama, P. (2022). How vegans, vegetarians and carnists differ in personality traits

and attitudes towards animals. Current Issues in Personality Psychology, 10(2), 147-152.

RECEIVED 11.03.2021 · REVIEWED 20.04.2021 · ACCEPTED 01.06.2021 · PUBLISHED 01.07.2021 


\section{BACKGROUND}

Diet plays a big role in human life from a young age, as children are taught what is eatable and what is not. Food, in general, is also related to many different cultural and regional patterns, but personality traits seems to play an important role too. The main robust individual differences in behaviour are present in the Big Five model (Lunn et al., 2014; McCrae \& John, 1992; Soto \& John, 2017), which makes it an ideal tool for exploring variation among different diet groups. In previous research, personality has already been linked to the type of food we eat and prefer (Conner et al., 2017; Keller \& Siegrist, 2015; Lunn et al., 2014; Tiainen et al., 2013). However, dietary preferences are not predicted only by general personality factors. In previous studies such variables as attitudes (e.g., political, environmental or animal attitude), age, sex or education have been shown to be comparably useful in the prediction of food preferences (e.g., Pfeiler \& Egloff, 2018a, b). Particularly the attitude towards animals may be strongly connected to dietary preference due to ethical reasons (Fox \& Ward, 2008; Kessler et al., 2016; Rothgerber, 2015; Ruby, 2012) as well as ecological and health reasons (Kessler et al., 2016; Phillips, 2005; Radnitz et al., 2015).

Prior research of personality traits and food preference revealed that openness to experience was positively connected with consumption of fruit and vegetables, while consumption of meat and soft drinks was in an opposite relationship with openness (Conner et al., 2017; Keller \& Siegrist, 2015; Pfeiler \& Egloff, 2018b). In general, openness represented healthier dietary practices (Lunn et al., 2014). For agreeableness, the results were rather contradictory. Some researchers found a negative correlation of agreeableness with meat consumption (Keller \& Siegrist, 2015; Pfeiler \& Egloff, 2018b). On the other hand, Conner et al. (2017) found that agreeableness did not predict consumption of fruit or vegetables. Conscientiousness was associated with the consumption of produce and also with a healthy lifestyle (Lunn et al., 2014), which was manifested by a lower BMI score (Keller \& Siegrist, 2015). Neuroticism correlated positively with sweet and savoury food (Keller \& Siegrist, 2015) and with a generally poorer dietary intake (traditional and convenient dietary pattern) (Lunn et al., 2014; Tiainen et al., 2013). Extraversion was related to consumption of vegetables (Keller \& Siegrist, 2015; Tiainen et al., 2013) and fruit (Conner et al., 2017).

Studies focusing explicitly on the personality traits of vegans, vegetarians or carnists/omnivores are relatively scarce. Prior research into this topic revealed that vegetarians/vegans differ from individuals who eat meat in gender, education, age, personality, level of trust, political views and current health status (Pfeiler \& Egloff, 2018a). Moreover, this study showed that non-meat eaters scored higher in openness and lower in conscientiousness. The other studies also confirmed higher openness in vegetarians (Aslanifar et al., 2014; Forestell \& Nezlek, 2018), but the results for neuroticism were rather contradictory. Forestell and Nezlek (2018) found that vegetarians are more neurotic and depressed than meat-eaters, but Aslanifar et al. (2014) revealed lower neuroticism and higher happiness among vegetarians. Kessler et al. (2016) showed that vegans scored lower in neuroticism and higher in openness than vegetarians. Concerning socio-demographic factors, vegetarians/vegans were younger, more educated compared to carnists, and 3 times as many women reported a meatless diet compared to men (Pfeiler \& Egloff, 2018a).

As mentioned above, attitudes can also play an important role in dietary preferences, where nonmeat eating groups, such as vegetarians, score considerably higher in positive moral attitudes towards animals than meat-eaters (Furnham et al., 2003; Herzog \& Golden, 2009; Ruby, 2012). Personality traits also matter; those who hold more positive attitudes towards animals are more agreeable, open and extraverted (Furnham et al., 2003). Vegans and vegetarians (to a lesser degree) were found to be highly supportive of animal rights, empathetic towards animals, reported being highly disgusted by meat, considered killing animals to be wrong and considered animals more human-like in emotional/cognitive capabilities (Bilewicz et al., 2011; Kessler et al., 2016; Rothgerber, 2015). In addition, women expressed more concern about animal suffering, were more likely to advocate for animal rights, and showed more compassion and care for animals than men did (Apostol et al., 2013; Herzog et al., 1991, 2015).

The main goal of our study was to investigate whether vegans, vegetarians and carnists differ in Big Five personality traits and in attitudes towards animals. Based on previous research findings, we hypothesize that vegans and vegetarians will score higher in open-mindedness and in attitudes towards animals than carnists. We also aimed to analyse how personality traits predict attitudes towards animals. We hypothesized that higher agreeableness and open-mindedness would be predictors of positive attitudes towards animals. We also assumed that women would have a more positive attitude towards animals.

\section{PARTICIPANTS AND PROCEDURE}

\section{PARTICIPANTS}

The participants filled out an online survey written in the Slovak language and distributed via social networks. In addition to a general invitation, we intentionally sent an invitation to participate in the study to vegetarian and/or vegan social network groups. The convenience sampling method yielded 190 par- 
ticipants; 57 of them labelled themselves as vegans, 56 as vegetarians, and 77 as carnists. The age of the sample was between 18 and 64 years $(M=24.90$, $S D=7.18)$. There were $134(70.5 \%)$ women and 56 men $(29.5 \%)$, of whom 43 women were vegans, 40 vegetarians and 51 carnists. From men, 14 were vegans, 16 vegetarians and 26 carnists. The vast majority of the participants had completed high school (53.7\%) or received higher education (37.9\%). All participants were from Slovakia. Participation in the study was voluntary, anonymous and all respondents provided informed consent before participation. The data file together with other materials is publicly available at https://osf.io/8afm7/.

\section{MEASURES}

We used standard items for demographic data: gender (man, woman) and education (basic, high school, university). To assess membership in the diet groups, we used a single question "What is your type of diet?" with three options: vegetarian (I do not eat meat or fish), vegan (I do not eat meat, fish, eggs or any dairy products) and I eat almost everything, which may include meat, fish, eggs and dairy products.

Big Five Inventory-2. For measuring personality traits, we used the Big Five Inventory-2 (BFI-2) developed by Soto and John (2017), which was translated and adapted to the Slovak language by Halama et al. (2020). The BFI- 2 consists of 60 items, and each of the five domains has 12 items. Every domain is composed of three facets as follows: extraversion (sociability, assertiveness, energy level), agreeableness (compassion, respectfulness, trust), conscientiousness (organization, productiveness, responsibility), negative emotionality (anxiety, depression, emotional volatility), open-mindedness (intellectual curiosity, aesthetic sensitivity, creative imagination). Items are answered on a five-point scale: strongly disagree, disagree a little, neutral or no opinion, agree a little, strongly agree. Cronbach's $\alpha$ coefficient obtained from the Slovak adaptation of the BFI-2 (Halama et al., 2020) ranged from .79 to .83 ; the lowest $\alpha$ was for the domain of open-mindedness. In our study Cronbach's $\alpha$ reached a similar level, as it ranged from .76 to .90; the lowest $\alpha$ was for open-mindedness and the highest for negative emotionality.

Animal Attitude Scale. For attitude towards animals, we used the Animal Attitude Scale 10-item version (AAS-10), which is a short form of the attitude scale developed by Herzog et al. (2015). A higher score indicates a more protective attitude towards animals, including concern for animal welfare and rejection of unethical behaviour towards animals. We translated the AAS-10 scale from English to Slovak following consensual translation. The scale consists of 10 items, e.g. "It is morally wrong to hunt wild animals just for sport”. The participants' answers were captured on a five-point scale: strongly agree, agree, neutral or no opinion, disagree, strongly disagree. Cronbach's $\alpha$ coefficient for ASS-10 in the original study was .82 (Herzog et al., 2015). In our case, Cronbach's $\alpha$ was .81 and all items contributed to the reliability approximately to the same extent and none of them compromised internal consistency.

\section{RESULTS}

In the first step, we conducted one-way ANOVA of personality traits in groups according to the dietary preferences. The ANOVA analysis revealed a significant difference between the diet groups in openmindedness $F(2,187)=8.43, p<.001$, partial $\eta^{2}=.083$, yet, in the remaining BFI-2 domains (extraversion, agreeableness, conscientiousness and negative emotionality) the diet groups did not differ significantly (see Table 1). Post-hoc comparison using Tukey's HSD test revealed that vegans $(M=4.18, S D=0.53)$ and vegetarians $(M=4.18, S D=0.54)$ scored higher in open-mindedness than carnists $(M=3.86, S D=0.50)$ by a difference of $d=-0.62,90 \%$ CI $[-0.91,-0.33]$ and $d=-0.61,90 \%$ CI $[-0.91,-0.32]$ respectively. The difference in open-mindedness between vegans and vegetarians was not statistically significant.

\section{Table 1}

Results of ANOVA of trait levels in the diet groups

\begin{tabular}{lcccccc}
\hline & $\begin{array}{c}\text { Vegans } \\
M(S D)\end{array}$ & $\begin{array}{c}\text { Vegetarians } \\
M(S D)\end{array}$ & $\begin{array}{c}\text { Carnists } \\
M(S D)\end{array}$ & $F$ & $p$ & Partial $\eta^{2}$ \\
\hline Open-mindedness & $4.18(0.52)$ & $4.18(0.54)$ & $3.86(0.50)$ & 8.43 & $<.001$ & .083 \\
Extraversion & $3.45(0.66)$ & $3.42(0.61)$ & $3.50(0.67)$ & 0.27 & .767 & .003 \\
Agreeableness & $3.87(0.63)$ & $3.76(0.69)$ & $3.90(0.54)$ & 0.87 & .420 & .009 \\
Conscientiousness & $3.44(0.72)$ & $3.31(0.83)$ & $3.36(0.73)$ & 0.40 & .669 & .004 \\
Negative emotionality & $2.94(0.92)$ & $3.12(0.82)$ & $2.79(0.82)$ & 2.40 & .095 & .025 \\
\hline
\end{tabular}


We also performed another analysis at the facet level. The results showed that vegans and vegetarians differed from carnists in two of three open-mindedness facets: intellectual curiosity $(F(2,187)=6.75$, $p<.001$, partial $\left.\eta^{2}=.067\right)$ and aesthetic sensitivity $F(2,187)=6.79, p<.001$, partial $\left.\eta^{2}=.068\right)$. In both cases, vegans and vegetarians scored higher than carnists. No difference was found for creative imagination $\left(F(2,187)=1.61\right.$, n.s., partial $\left.\eta^{2}=.016\right)$. From other facets, only sociability showed a significant difference between the groups $(F(2,187)=3.69, p=.027)$ with higher scores for carnists in comparison to vegans and vegetarians, although the effect was smaller (partial $\left.\eta^{2}=.037\right)$.

Another one-way ANOVA was conducted to determine whether the diet groups differ in their attitude towards animals. In this case, the data violated the assumption of homogeneity of variance, so we used Welch's ANOVA. The analysis yielded a significant difference in attitudes towards animals between these groups; $F(2,123.66)=89.91, p<.001$, partial $\eta^{2}=.516$. Games-Howell post hoc analysis revealed that vegans $(M=45.44, S D=4.24)$ and vegetarians $(M=43.77, S D=4.48)$ scored higher in AAS compared to carnists $(M=34.14, S D=5.94)$ at a significance level of $p<.001$ and $p<.001$ respectively. The difference in attitudes towards animals between vegans and vegetarians was not statistically significant.

To assess the relationship of dietary preferences to demographic variables, we conducted a chi-squared test of the relationship between gender and dietary preferences as well as between education and dietary preferences. Both tests revealed no significant relationship between these groups $\left(\chi^{2}=1.36\right.$, n.s. for gender, $\chi^{2}=3.42$, n.s. for education). Another one-way
ANOVA was performed to analyse differences in age between the diet groups. The analysis showed that vegans, vegetarians and carnists in our sample did not differ in age $[F(2,187)=2.34$, n.s. $]$.

A multiple regression analysis was run to predict attitudes towards animals from personality traits controlled for gender, age and education. The multiple regression model statistically significantly predicted attitudes towards animals $F(8,181)=4.59$, $p<.001$, adj. $R^{2}=.13$. Only one variable significantly added to the prediction: open-mindedness $(\beta=.36$, $p<.001)$. The results of multiple regression analysis with regression coefficients and standard errors can be found in Table 2 .

The regression analysis with facets instead of domains revealed that facets predicted slightly more variance of attitudes towards animals, $F(18,171)=3.58$, $p<.001$, adj. $\left.R^{2}=.20\right)$. The only open-mindedness facet independently predicting attitudes towards animals was aesthetic sensitivity $(\beta=.21, p<.01)$. From other facets, sociability (extraversion) was a negative predictor $(\beta=-.28, p<.01)$ and energy level (extraversion) was a positive predictor of attitudes towards animals $(\beta=.33, p<.001)$.

\section{DISCUSSION}

This present study reconfirms some of the previous findings while exploring the intervening role of attitudes towards animals. The analysis of differences showed that in our convenient sample, vegans, vegetarians and carnists do significantly differ in personality and in attitude towards animals. Both the vegan and vegetarian groups scored higher than carnists in

Table 2

Multiple regression results for attitudes towards animals

\begin{tabular}{|c|c|c|c|c|c|}
\hline \multirow[t]{2}{*}{ Animal Attitude Scale } & \multirow[t]{2}{*}{$B$} & \multicolumn{2}{|c|}{$95 \% \mathrm{Cl}$ for $B$} & \multirow[t]{2}{*}{$S E B$} & \multirow[t]{2}{*}{$\beta$} \\
\hline & & LL & UL & & \\
\hline Constant & $15.43^{*}$ & 0.01 & 30.86 & 7.82 & \\
\hline Gender & -1.69 & -3.98 & 0.60 & 1.16 & -.11 \\
\hline Age & 0.08 & -0.07 & 0.22 & 0.07 & .07 \\
\hline Education & -0.04 & -1.70 & 1.62 & 0.84 & .00 \\
\hline Agreeableness & -0.12 & -1.91 & 1.63 & 0.91 & -.01 \\
\hline Open-mindedness & $4.78^{* * *}$ & 2.91 & 6.64 & 0.95 & $.36^{* * *}$ \\
\hline Negative emotionality & 0.95 & -0.50 & 2.40 & 0.74 & .11 \\
\hline Conscientiousness & 1.20 & -0.20 & 2.60 & 0.71 & .13 \\
\hline Extraversion & -0.11 & -1.85 & 1.68 & 0.88 & -.01 \\
\hline
\end{tabular}

Note. Adj. $R^{2}=.13^{* * *}$; gender coded 1 - women, 2 - men; B - unstandardized regression coefficient; $\mathrm{Cl}$ - confidence interval; LL - lower limit; UL - upper limit; SE $B$ - standard error of the coefficient; $\beta$ - standardized coefficient; ${ }^{*} p<.05,{ }^{* *} p<.01,{ }^{* * *} p<.001$. 
open-mindedness, which was expected. Open-mindedness as a trait reflects sensitivity, intellectual curiosity, unconventionality and the ability to consider new ethical and social views (Rothmann \& Coetzer, 2003). The trait itself is related to healthy dietary preferences, which is negatively related to meat consumption (Keller \& Siegrist, 2015; Lunn et al., 2014; Pfeiler \& Egloff, 2018b). There is no evidence that vegans score higher in open-mindedness than vegetarians. The diet groups did not differ significantly in the remaining personality traits.

In the attitudes towards animals, vegans and vegetarians score significantly higher than carnists; however, there is no distinction between scores among vegans and vegetarians. This result corresponds with previous research, as non-meat eaters tend to score significantly higher than meat-eaters in attitudes towards animals (Herzog \& Golden, 2009; Ruby, 2012). Vegans and vegetarians care greatly about animal welfare (Fox \& Ward, 2008; Rothgerber, 2015; Ruby, 2012); they also tend to be more disgusted by meat and consider animals more human-like (Bilewicz et al., 2011; Kessler et al., 2016; Rothgerber, 2015). Therefore, it is not surprising to see such a disparity between vegans/vegetarians and carnists in attitudes towards animals. Attitudes towards animals are an important predictor of dietary preferences and should be taken into consideration in diet research. However, the difference between vegetarians and vegans was not significant.

Demographic variables have been frequently proven to be important in predicting dietary preferences (Pfeiler \& Egloff, 2018a, b). We assessed the relationship between the diet groups and our demographic variables, including gender, education and age, but none yielded a significant result. We assume two possible reasons. One is related to sample specificity, as our sample was convenient and relatively small. The second reason involves the fact that there could be some specific cultural factors which could have impacted our results. However, we are not able to find them with this sample. Nonetheless, we may observe a large gender imbalance in favour of women in previous research and theory. As Kessler et al. (2016) noted, vegetarianism is generally associated with women and feminineness.

We hypothesized that agreeableness and openmindedness and demographic variables, predominantly gender, will predict attitudes towards animals. The present findings supported only one of our assumptions. As shown by regression analysis, only open-mindedness was a significant predictor of attitudes towards animals. This result corresponds to the description of this trait as it reflects sensitivity, intellectual curiosity, originality, and the ability to consider new views and experience deeper emotions (Rothmann \& Coetzer, 2003). However, our assumptions about agreeableness were not met, even though the trait reflects altruistic behaviour, compassion and willingness to help others (Rothmann \& Coetzer, 2003). That leaves only open-mindedness as a variable that is consistent in our findings across different hypotheses. Among the demographic variables, women in previous research expressed more concern about animals and scored higher than men in attitudes towards animals (Apostol et al., 2013; Herzog et al., 1991, 2015), but our data did not support these findings. Neither gender, education nor age was a significant predictor of attitudes towards animals.

The limitations of our study include the exclusive use of self-report measures, especially the simple and self-report measure of food preferences status. Another limitation is the use of small convenience samples, which has consequences for possible effects detected. The rather small sample means lower statistical power of the test used, and some possible effects could have been overlooked. Another limitation is that we did not include the measure of other attitudes or ideologies behind the food preferences. There is some research on the role of conservative political values in vegetarian or carnist preferences, showing that right-wingers are usually meat eaters and vegans or vegetarians are more likely to be left-wingers (see Machado-Oliveira et al., 2020 for review), and this difference may be related to different levels of openness. Inclusion of such a measure could contribute to the understanding of how food preferences are shaped by ideology related to personality traits.

\section{FUNDING SOURCE}

This work was supported by the Scientific Grant Agency VEGA [grant number 1/0363/18].

\section{REFERENCES}

Apostol, L., Rebega, O. L., \& Miclea, M. (2013). Psychological and socio-demographic predictors of attitudes toward animals. Procedia - Social and Behavioral Sciences, 78, 521-525. https://doi. org/10.1016/j.sbspro.2013.04.343

Aslanifar, E., Fakhri, M. K., Mirzaian, B., \& Kafaki, H. B. (2014). The comparison of personality traits and happiness of vegetarians and non-vegetarians. In F. Uslu (Ed.), International Conference on Social Sciences and Humanities (pp. 1031-1037). Center of Academic Research.

Bilewicz, M., Imhoff, R., \& Drogosz, M. (2011). The humanity of what we eat: Conceptions of human uniqueness among vegetarians and omnivores. European Journal of Social Psychology, 41, 201-209. https://doi.org/10.1002/ejsp.766

Conner, T. S., Thompson, L. M., Knight, R. L., Flett, J. A. M., Richardson, A. C., \& Brookie, K. L. 
(2017). The role of personality traits in young adult fruit and vegetable consumption. Frontiers in Psychology, 8, 1-11. https://doi.org/10.3389/fpsyg. 2017.00119

Forestell, C. A., \& Nezlek, J. B. (2018). Vegetarianism, depression, and the five-factor model of personality. Ecology of Food and Nutrition, 57, 246-259. https://doi.org/10.1080/03670244.2018.1455675

Fox, N., \& Ward, K. (2008). Health, ethics and environment: a qualitative study of vegetarian motivations. Appetite, 50, 422-429. https://doi.org/10.1016/j. appet.2007.09.007

Furnham, A., Mcmanus, C., \& Scott, D. (2003). Personality, empathy and attitudes to animal welfare. Anthrozoös, 16, 135-146. https://doi.org/10. 2752/089279303786992260

Halama, P., Kohút, M., Soto, C. J., \& John, O. P. (2020). Slovak adaptation of the Big Five Inventory (BFI-2): Psychometric properties and initial validation. Studia Psychologica, 62, 74-87. https:// doi.org/10.31577/sp.2020.01.792

Herzog, H. A., Betchart, N. S., \& Pittman, R. B. (1991). Gender, sex role orientation, and attitudes toward animals. Anthrozoös, 4, 184-191. https://doi. org/10.2752/089279391787057170

Herzog, H. A., \& Golden, L. L. (2009). Moral emotions and social activism: The case of animal rights. Journal of Social Issues, 65, 485-498. https://doi. org/10.1111/j.1540-4560.2009.01610.x

Herzog, H. A., Grayson, S., \& Mccord, D. M. (2015). Brief measures of the Animal Attitude Scale. Anthrozoös, 28, 145-152. https://doi.org/10.2752/0892 79315X14129350721894

Keller, C., \& Siegrist, M. (2015). Does personality influence eating styles and food choices? Direct and indirect effects. Appetite, 84, 128-138. https://doi. org/10.1016/j.appet.2014.10.003

Kessler, C. S., Holler, S., Joy, S., Dhruva, A., Michalsen, A., Dobos, G., \& Cramer, H. (2016). Personality profiles, values and empathy: Differences between lacto-ovo-vegetarians and vegans. Forsch Komplementmed, 23, 95-102. https://doi.org/10. 1159/000445369

Lunn, T. E., Nowson, C. A., Worsley, A., \& Torres, S. J. (2014). Does personality effects dietary intake? $\mathrm{Nu}$ trition, 30, 403-409. https://doi.org/10.1016/j.nut. 2013.08.012

Machado-Oliveira, M. C., Nezlek, J. B., Rodrigues, H., \& Sant'Ana, A. S. (2020). Personality traits and food consumption: an overview of recent research. Current Opinion in Food Science, 33, 91-97. https:// doi.org/10.1016/j.cofs.2020.02.005

McCrae, R. R., \& John, O. P. (1992). An introduction to the Five-Factor model and its applications. Journal of Personality, 60, 175-215. https://doi. org/10.1111/j.1467-6494.1992.tb00970.x

Pfeiler, T. M., \& Egloff, B. (2018a). Examining the "veggie" personality: Results from a representative
German sample. Appetite, 120, 246-255. https:// doi.org/10.1016/j.appet.2017.09.005

Pfeiler, T. M., \& Egloff, B. (2018b). Personality and attitudinal correlates of meat consumption: Results of two representative German samples. Appetite, 121, 294-301. https://doi.org/10.1016/j.appet.2017.11.098 Phillips, F. (2005). Vegetarian nutrition. Nutrition Bulletin, 30, 132-167. https://doi.org/10.1111/j.14673010.2005.00467.x

Radnitz, C., Beezhold, B., \& Dimatteo, J. (2015). Investigation of lifestyle choices of individuals following a vegan diet for health and ethical reasons. Appetite, 90, 31-36. https://doi.org/10.1016/j.appet. 2015.02.026

Rothgerber, H. (2015). Underlying differences between conscientious omnivores and vegetarians in the evaluation of meat and animals. Appetite, 87, 251258. https://doi.org/10.1016/j.appet.2014.12.206

Rothmann, S., \& Coetzer, E. P. (2003). The Big Five personality dimensions and job performance. Journal of Industrial Psychology, 29, 68-74. https:// doi.org/10.4102/sajip.v29i1.88

Ruby, M. B. (2012). Vegetarianism. A blossoming field of study. Appetite, 58, 141-150. https://doi. org/10.1016/j.appet.2011.09.019

Soto, C. J., \& John, O. P. (2017). The next Big Five Inventory (BFI-2): Developing and assessing a hierarchical model with 15 facets to enhance bandwidth, fidelity, and predictive power. Journal of Personality and Social Psychology, 113, 117-143. https://doi.org/10.1037/pspp0000096

Tiainen, A. M., Männistö, S., Lahti, M., Blomstedt, P. A., Lahti, J., Perälä, M. M., Räikkönen, K., Kajantie, E., \& Eriksson, J. G. (2013). Personality and dietary intake - findings in the Helsinki birth cohort study. PLoS One, 8, 1-8. https://doi.org/10.1371/journal. pone. 0068284 